\title{
Quantitative evaluation of an information leaflet to increase prompt help-seeking for gynaecological cancer symptoms
}

\author{
Melanie Morris ${ }^{1,2}$, Claire Friedemann Smith ${ }^{1}$, Emily Boxell ${ }^{1}$, Jane Wardle ${ }^{1 \uparrow}$, Alice Simon ${ }^{1,3}$ and Jo Waller ${ }^{1 *}$
}

\begin{abstract}
Background: Provision of written information may improve awareness of cancer symptoms and encourage timely presentation in primary care. This study assessed changes in symptom knowledge, perceived barriers to help-seeking, anxiety and intention to seek help, following exposure to a leaflet to raise awareness of gynaecological cancer symptoms.
\end{abstract}

Methods: Women $(N=484)$ completed questionnaires before and after reading the leaflet. The primary outcome was change in anticipated time to help-seeking for 12 symptoms. Changes in symptom knowledge, barriers and anxiety, and their association with prompt help-seeking were evaluated using Wilcoxon signed rank tests and logistic regression analyses.

Results: After reading the leaflet, symptom knowledge increased $(p<0.001)$, and perceived barriers $(p<0.001)$ and anxiety $(p=0.008)$ decreased. The number of symptoms for which women anticipated seeking help promptly increased ( $p<0.001$ ). Changes in knowledge (OR 4.21, 95 \% Cl 1.95-9.13) and perceived barriers (OR 4.60, 95 \% Cl 1.9111.04) were independently associated with increased help-seeking.

Conclusion: Increased symptom knowledge and lowered perceived barriers were related to increased prompt anticipated help-seeking. This occurred without an increase in anxiety. This intervention is effective in altering knowledge, beliefs and help-seeking intentions for gynaecological cancer symptoms, at least in the short-term, and should be trialled in primary care.

Keywords: Gynaecological cancer, Help-seeking, Knowledge, Barriers, Anxiety, Leaflet, Early diagnosis

\section{Background}

Gynaecological cancers are a significant burden in the United Kingdom (UK): they have a combined incidence second only to breast cancer [1] and incidence is likely to rise as the population ages and becomes more overweight [2]. Some symptoms of gynaecological cancers can be present long before diagnosis [3], suggesting that earlier diagnosis could be made on the basis of these symptoms. However, some of these symptoms are relatively common and have a low positive predictive value [3-5] with the result that they may be mistaken for

\footnotetext{
* Correspondence: j.waller@ucl.ac.uk

'Deceased

'Health Behaviour Research Centre, University College London, 1-19

Torrington Place, London WC1E 7HB, UK

Full list of author information is available at the end of the article
}

symptoms of more benign conditions by patients and healthcare professionals alike [6]. Although in 2015 the National Institute for Health and Care Excellence (NICE) lowered the threshold at which patients should be referred for cancer diagnostic tests [7], if the patient herself does not recognise and act upon symptoms there is no opportunity for referral for investigations and early diagnosis.

Due to the progressive nature of cancer, much effort has been put into understanding what contributes to a shorter patient interval - the time taken for an individual to notice and interpret a new symptom as worthy of medical attention and to seek medical advice [8]. Shorter patient intervals could lead to earlier-stage diagnoses and improved survival $[9,10]$. Studies of women's levels of awareness of gynaecological cancer symptoms show 
that free recall of symptoms is low and, although prompted recognition is higher, most women still do not recognise all symptoms [11-13]. Furthermore some symptoms (e.g., abdominal pain) are well-recognised by women as important, while others (e.g., feeling full quickly and difficulty eating) are less well-known as possible symptoms of ovarian cancer [12]. When women experience these symptoms, they typically attribute them to benign causes rather than cancer [14], and may not seek a medical opinion promptly.

UK studies have reported that participants who do not recognise a symptom as being a cancer alarm symptom are more likely to anticipate waiting longer to seek help than those who do $[15,16]$. In addition, when General Practitioners (GPs) were asked what they thought caused delay in presentation for gynaecological cancer symptoms they agreed that patients' lack of knowledge was a substantial barrier [17]. This is consistent with the finding that knowledge that a symptom could be caused by cancer acts as a prompt to help-seeking [18]. However, there is a dearth of research on interventions to promote prompt help-seeking in this context [19].

The provision of information is an ongoing challenge for healthcare providers. Completeness of information must be balanced with considerations of the target population's health literacy and the importance of not inducing undue anxiety, which itself can be a barrier to helpseeking [20]. To date, the use of focus groups and other qualitative methods to develop and refine written information has dominated this area, while experimental evaluation of the impact of information leaflets is rare. Qualitative evaluations of health information leaflets tend to report descriptive results about whether the leaflet was found to be acceptable and comprehensible by the patients [21-23], and although this can be an important step in development, how effective written information is at changing attitudes or behaviours is still under-researched [24].

This study therefore represents a crucial, but oftenneglected stage of testing in leaflet development. It is an attempt to go beyond the focus groups and interviews [17] that have already informed the initial development of this leaflet, and obtain a quantitative measure of its immediate impact before testing its effect on consultation rates in primary care. This approach is in line with the Complex Interventions Guidance from the Medical Research Council (MRC) which emphasises the need for a 'development-evaluation-implementation' process, and for 'greater investment in developmental studies prior to large-scale evaluations' [25] (p33).

In the current study, we evaluated a leaflet designed for use in a primary care setting which aims to increase appropriate presentation of symptoms associated with gynaecological cancers. It does this by laying out the symptoms clearly, reassuring women about their potential concerns and including a checklist of symptoms that might empower them to take their concerns to a healthcare professional. We quantified the change, after reading the leaflet, in symptom knowledge, barriers to presentation and anxiety, and assessed whether these were related to anticipated prompt help-seeking.

\section{Methods \\ Recruitment}

We calculated that a sample size of 464 would be required to detect a small effect size of 0.26 , based on the changes reported in help-seeking intentions following a leaflet intervention in a previous study [26]. Women were recruited in and around London at ten Cancer Awareness Roadshows and seven Race for Life ${ }^{1}$ events (both runners and spectators). Race for Life events are specifically for women and the Roadshows visit deprived inner-city areas. In this way we reached a range of women who, despite a potential interest in cancer, would not necessarily have any more knowledge about symptoms than the general population. Women over 18 were consecutively invited to take part in the research, including those who had had a hysterectomy or a cancer diagnosis as the leaflet was still relevant for them, until the required sample size was reached. Women were offered fruit and drinks while participating, and given a supermarket trolley token in lieu of a financial incentive. Women read a participant information sheet and signed a consent form after being given the opportunity to ask questions. Participants were given a Cancer Research UK helpline card in case they had any further questions about cancer. Data were collected between April 2011 and August 2011.

\section{Protocol}

Women were approached to complete a questionnaire before (Time $1-\mathrm{T} 1$ ) and after (Time $2-\mathrm{T} 2$ ) reading the intervention leaflet. Health literacy was assessed before the first questionnaire using a verbal health literacy assessment (Newest Vital Sign - NVS [27]) which has been validated for use in the UK [28]. Demographic information was collected in the second questionnaire. Questionnaires were completed either in a paper and pencil format or on a laptop computer on which an identical questionnaire was laid out. Researchers were trained in the protocol to ensure consistency of administration. The process took approximately $30 \mathrm{~min}$ for each participant. Ethical approval was granted by the University College London (UCL) Research Ethics Committee (reference 1122/004). 


\section{Materials \\ Leaflet}

The leaflet was previously developed through an iterative process involving consultations with six experts in the field, one-to-one interviews with three gynaecological cancer survivors, and three focus groups (two with nonsymptomatic women, one with survivors). The leaflet contains a GP's message inviting women to come forward with any concerns; introduces the five gynaecological cancers with a diagram of the female reproductive system; and lists the symptoms of the gynaecological cancers. It deals with common concerns, and attempts to reassure women about potential embarrassment or worry. Finally, it includes a symptom checklist on which women could record any symptoms they have had and note when they started. The leaflet ends with a 'call to action' for women with any symptoms to call their GP surgery for an appointment (Additional file 1).

\section{Questionnaire}

The questionnaire measures were derived from the Ovarian Cancer Awareness Measure and the Cervical Cancer Awareness Measure (CAM) [29] with the addition of specific questions about symptoms relevant to the leaflet. Demographic characteristics were assessed using questions from the Office for National Statistics [30]. The questionnaires were piloted with members of the public $(N=12)$ and amended according to comments.

Knowledge of symptoms Women's recognition of gynaecological cancer symptoms was assessed by presenting a list of 12 symptoms and asking them to indicate which ones were warning signs of gynaecological cancers. All of the symptoms presented were in fact correct symptoms. Women's symptom knowledge was summed both before and after exposure to the leaflet, giving a range from 0 to 12 at each time point.

A symptom knowledge change score was calculated for each woman by subtracting knowledge scores achieved before the leaflet (T1) from those after the leaflet (T2). This continuous variable was grouped for the logistic regression analyses into three categories: 1) no change or a reduction in knowledge, 2) a small increase in knowledge (one to six symptoms), or 3) a large increase (seven or more symptoms).

Barriers Women's perceived barriers to help-seeking were also assessed with questions from the CAM [31]. Here the women were presented with a list of 10 potential barriers including four emotional barriers (e.g., embarrassment), three practical barriers (e.g., too busy) and three service barriers (e.g., worried about wasting doctor's time) [16]. For each barrier they were asked to answer 'yes often' (coded as 1), 'yes sometimes' (coded 1 ), 'no' (coded 0) or 'don't know' (coded as missing). Scores were summed to give a barrier score (range 0 to 10) at both $\mathrm{T} 1$ and $\mathrm{T} 2$.

A barrier change score was calculated by subtracting the number of barriers reported at $\mathrm{T} 1$ from the number reported at T2. For some analyses this was grouped into three categories: 1) an increase or no change in barriers, 2) a small reduction in barriers (one to two) and 3) a large reduction in barriers (two or more).

Anxiety The short form of the State-Trait Anxiety Inventory (STAI) [32] was used to assess women's anxiety levels at the start of each questionnaire. The 6 item scale has a range of 6 to 24, with higher scores indicating greater anxiety. Scores were imputed for women who had missing data if they had answered more than half (>3) of the items, by calculating a mean score from the completed items. An anxiety change score was calculated by subtracting the STAI score at T1 from the score at T2. These were also grouped into three categories: 1) a large reduction in anxiety (by seven or more points), 2) a small reduction in anxiety (by one to six points), and 3) no change or an increase in anxiety.

Anticipated time to help-seeking Anticipated time to seeking help from the GP was measured using questions derived from the CAM [31]. Initially each woman was asked to indicate how quickly she might go to the doctor for each of the 12 symptoms using ten time categories ranging from ' 1 to 3 days' to 'never'. A score was developed from these answers to give a measure of the speed with which each woman anticipated seeking help compared to the other women in the sample. Although previous studies have explored anticipated help-seeking using a somewhat arbitrary cut-off of two weeks [16], the symptoms assessed in this study varied greatly in their urgency and no overall guidance exists for appropriate clinically-meaningful cut-offs. Therefore, for each symptom women were dichotomised into those who intended to seek help by the median-chosen category or sooner (coded as 1), and those who would wait longer than the median (coded as 0). Attending before the median was considered prompt help-seeking, as it was faster than the average in the sample. Scores were then summed across all 12 symptoms (range $0-12$ ) to give a "promptness score" with higher scores indicating prompt help-seeking for a greater number of symptoms.

For responses at $\mathrm{T} 2$ the same method was used, but maintaining the medians used at $\mathrm{T} 1$ as the cut-offs, so that anticipated time to help-seeking at T2 could be compared with women's T1 responses. A binary change score was created for use in the logistic regression analysis: women who would seek help promptly for more 
symptoms at T2 were coded as 1, and those who would seek help promptly for the same number or fewer symptoms at T2 were coded as 0.

Demographic characteristics For the analyses, age was grouped into five categories $(18-29,30-39,40-49,50-$ 59 , and over 60 years old) and ethnicity was dichotomised into White/non-White. Education level was used as a proxy for socio-economic status with three levels defined: no formal qualifications, school-level qualifications and higher-education qualifications.

Health literacy Health literacy was measured by the NVS (see above), and was grouped into three categories; low ( $0-1$ points), marginal ( $2-3$ points), and adequate literacy (4-6 points).

\section{Statistical analysis}

Changes in reported symptom knowledge, barriers, anxiety and anticipated time to help-seeking from T1 to T2 were evaluated using Wilcoxon signed rank tests. Univariate and multivariate binary logistic regression analyses were performed to measure the extent to which change in knowledge score, change in barriers score, and change in anxiety score were associated with a change in anticipated help-seeking, using the binary outcome variable described above. Age, ethnicity, education, and health literacy were included in all the multivariate models as they are known from previous research to be associated with help-seeking behaviour.

Analyses were carried out using SPSS Version 20.

\section{Results}

\section{Sample characteristics}

A sample of 484 women was recruited. Table 1 shows the demographic characteristics of the sample: $43 \%$ $(n=207)$ were over 40 years old (mean $=41$ years, SD $=14$ years, range 18 to 83 years). Half had a higher degree (54\%, $n=260)$, and the majority scored in the 'adequate' range for health literacy $(58 \%, n=282)$. The sample was more ethnically varied than the UK population, with a quarter of women from non-white ethnic minority groups $(25 \%, n=119)$. Almost a third of women (32\%, $n=148)$ reported experiencing symptoms in the last three months, but very few participants had had a diagnosis of gynaecological cancer themselves $(<3 \%, n=12)$. However $38 \%$ knew someone who had ( $n=176$, data not shown).

\section{T1 responses}

At $\mathrm{T} 1$, the median time that women anticipated waiting before seeking help varied across symptoms from 1 week (for pelvic/abdominal pain that doesn't go away, persistent vaginal discharge with an unpleasant odour, soreness
Table 1 Characteristics of sample $(n=484)$

\begin{tabular}{lll}
\hline & Number & Percent \\
\hline Age & 113 & 23.3 \\
$18-29$ & 95 & 19.6 \\
$30-39$ & 94 & 19.4 \\
$40-49$ & 61 & 12.6 \\
$50-59$ & 52 & 10.7 \\
$60+$ & 69 & 14.3 \\
Missing & & \\
Ethnicity & 348 & 71.9 \\
White & 119 & 24.6 \\
Other ethnic backgrounds & 17 & 3.5 \\
Missing & & \\
Highest qualification & 37 & 7.6 \\
No formal qualifications & 147 & 30.4 \\
School education (A levels or GCSEs) & 260 & 53.7 \\
Higher education (degree or above) & 40 & 8.3 \\
Missing & & \\
Health Literacy & 120 & 3.7 \\
Low (0-1) & 282 & 13.2 \\
Marginal (2-3) & & \\
Adequate (4-6) & & \\
Missing & & \\
\hline
\end{tabular}

or lump on the vulva) up to 6 weeks (for longer of heavier periods than usual) (Table 2). At T1 the mean score for symptom knowledge was $6.6(\mathrm{SD}=3.3)$, for barriers endorsed was $3.5(\mathrm{SD}=2.5)$, and for anxiety was 12.8 $(\mathrm{SD}=4.5)$.

\section{Changes from $\mathrm{T} 1$ to $\mathrm{T} 2$}

The median time that women would wait before seeking help was reduced after reading the leaflet across all symptoms, with the greatest reduction for "Longer or heavier periods". The number who anticipated never seeking help for each symptom was reduced by at least half, and up to $77 \%$ for lump or soreness on vulva and longer or heavier periods (Table 2).

Symptom knowledge, barriers, anxiety levels and anticipated time to help-seeking were all significantly different after the intervention. Symptom knowledge increased from a mean of 6.6 symptoms recognised per woman to 10.1 (out of a maximum of $12, p<0.001$ ) (Table 3). Reported barriers to help-seeking reduced from a mean of 3.5 to 2.5 (out of a possible $10, p<$ 0.001 ). Anxiety reduced slightly from a score of 12.8 to 12.0 (range 6 to $24, p=0.008$ ).

Before reading the leaflet, $21 \%$ of women anticipated seeking help for every one of the 12 symptoms quicker than the median category chosen (i.e., they had a 
Table 2 Anticipated time to help-seeking for each symptom before and after reading the leaflet

\begin{tabular}{|c|c|c|c|c|}
\hline \multirow[b]{2}{*}{ Symptom given in the questionnaire } & \multicolumn{2}{|c|}{$\begin{array}{l}\text { Median anticipated time to help- } \\
\text { seeking }\end{array}$} & \multicolumn{2}{|c|}{$\begin{array}{l}\text { Number (\%) of women anticipating never seeking } \\
\text { help for symptom }\end{array}$} \\
\hline & $\begin{array}{l}\text { Time } 1 \\
\text { (pre-intervention) }\end{array}$ & $\begin{array}{l}\text { Time } 2 \\
\text { (post-intervention) }\end{array}$ & $\begin{array}{l}\text { Time } 1 \\
\text { (pre-intervention) }\end{array}$ & $\begin{array}{l}\text { Time } 2 \text { ( } \\
\text { post-intervention) }\end{array}$ \\
\hline Pelvic/abdominal pain that doesn't go away & 1 week & $4-6$ days & $11(2 \%)$ & $5(1 \%)$ \\
\hline Persistent vaginal discharge with an unpleasant odour & 1 week & 4-6 days & $26(5 \%)$ & $8(2 \%)$ \\
\hline Soreness or lump on the vulva (outer part of the vagina) & 1 week & 4-6 days & $42(9 \%)$ & $14(3 \%)$ \\
\hline Bleeding after the menopause & 2 weeks & 1 week & $32(7 \%)$ & $14(3 \%)$ \\
\hline Vaginal bleeding between periods & 2 weeks & 1 week & $20(4 \%)$ & $8(2 \%)$ \\
\hline Lower back pain that doesn't go away & 2 weeks & 1 week & $31(6 \%)$ & $16(3 \%)$ \\
\hline Persistent diarrhoea or other changes in bowel habits & 2 weeks & 1 week & $15(3 \%)$ & $8(2 \%)$ \\
\hline Bloating / swollen tummy & 1 month & 1 week & $56(12 \%)$ & $20(4 \%)$ \\
\hline Loss of appetite / feeling full quickly & 1 month & 1 week & $81(17 \%)$ & $24(5 \%)$ \\
\hline Pain / discomfort during sex & 1 month & 1 week & $41(9 \%)$ & $17(4 \%)$ \\
\hline Needing the toilet more often or more urgently & 1 month & 1 week & $25(5 \%)$ & $12(3 \%)$ \\
\hline Longer or heavier periods than usual & 6 weeks & 1 week & $45(9 \%)$ & $15(3 \%)$ \\
\hline
\end{tabular}

promptness score of 12). However after reading the leaflet, that proportion doubled to $43 \%$, and the proportion who did not anticipate seeking help quicker than the median for any symptom (promptness score $=0$ ) also decreased (from 10 to $7 \%$ ). The mean number of symptoms for which women would seek help more quickly than the median increased from 6.8 symptoms before exposure to the leaflet, to 8.8 symptoms after $(p<0.001)$.

\section{Binary logistic regression analysis}

In univariate analyses (Table 4), an increase in the number of symptoms for which women would seek help promptly was significantly associated with being more highly educated (OR 2.59, 95 \% CI 1.29-5.53), an adequate health literacy score (OR 1.77, $95 \%$ CI 1.01-3.10), both a small increase (OR 2.55, $95 \% \mathrm{CI}$ 1.54-4.20) and a large increase (OR 4.63, $95 \%$ CI 2.62-8.21) in the participants' symptom knowledge, and both a small and a large reduction in the number of barriers endorsed (OR 1.82, $95 \%$ CI 1.22-2.73 and OR 3.91, 95 \% CI 2.08-7.34 respectively). Conversely, being of non-white ethnicity was associated with a reduced likelihood of prompt help-seeking (OR 0.64, 95 \% CI 0.42-0.98).

After adjustment for the other variables in the model (Table 4), non-white women were still around half as likely as white women to seek help promptly for more symptoms (OR 0.54, 95 \% CI 0.29-0.98). Reductions found in anxiety scores led to more prompt help-seeking than when anxiety stayed the same or increased, but these associations were not significant. However, positive changes in symptom knowledge and in barriers were both significantly associated with large increased odds of prompt helpseeking after adjustment: a small increase (OR 2.68, $95 \%$ CI 1.32-5.44) or a large increase in knowledge (OR 4.21, 95 \% CI 1.95-9.13), as well as a small reduction (OR 1.84, 95 \% CI 1.07-3.17), or a large reduction in barriers score (OR 4.60, 95 \% CI 1.9111.04) were all associated with prompt anticipated help-seeking for more symptoms.

\section{Discussion}

This quantitative approach to the evaluation of an information leaflet for gynaecological cancer demonstrated a

Table 3 Unadjusted mean scores before and after the intervention (only respondents at T1 and T2 included)

\begin{tabular}{lllll}
\hline & $N$ & Time 1 (Pre-intervention) Mean (SD) & Time 2 (Post-intervention) Mean (SD) & Wilcoxon Signed Rank Test: $p$ value \\
\hline Symptom knowledge $^{a}$ & 483 & $6.56(3.30)$ & $10.10(3.27)$ & $p<0.001$ \\
Barriers to help-seeking $^{b}$ & 472 & $3.46(2.51)$ & $2.46(2.51)$ & $p<0.001$ \\
Anxiety score $^{c}$ & 401 & $12.83(4.50)$ & $12.01(4.48)$ & $p=0.008$ \\
Anticipated help-seeking $^{d}$ & 484 & $6.82(4.15)$ & $8.75(3.95)$ & $p<0.001$ \\
\hline
\end{tabular}

${ }^{a}$ Number of symptoms recognised: range of scores $0-12$

${ }^{\mathrm{b}}$ Number of barriers endorsed: range of scores $0-10$

'Short version STAI: range of scores 6-24

${ }^{\mathrm{d}}$ Number of symptoms for which the woman would go to the doctor more quickly than the Time 1 median 
Table 4 Predictors of prompt anticipated help-seeking for more symptoms at Time 2 than Time 1 (excludes missing data)

\begin{tabular}{|c|c|c|c|c|c|}
\hline & \multirow[b]{2}{*}{$\begin{array}{l}\text { Increase in prompt help-seeking } \\
\text { score at T2, n (row \%) }\end{array}$} & \multicolumn{2}{|c|}{$\begin{array}{l}\text { Univariate logistic } \\
\text { regression (unadjusted) }\end{array}$} & \multicolumn{2}{|c|}{$\begin{array}{l}\text { Multivariate logistic } \\
\text { regression (adjusted) }\end{array}$} \\
\hline & & Odds ratio & $95 \% \mathrm{Cl}$ & Odds Ratio & $95 \% \mathrm{Cl}$ \\
\hline \multicolumn{6}{|l|}{ Age } \\
\hline $18-29(113,27 \%)$ & $76(68 \%)$ & 1.00 & & 1.00 & \\
\hline $30-39(95,23 \%)$ & $55(60 \%)$ & 0.70 & $0.40-1.25$ & 0.88 & $0.44-1.75$ \\
\hline $40-49(94,23 \%)$ & $57(61 \%)$ & 0.73 & $0.41-1.29$ & 1.00 & $0.49-2.02$ \\
\hline $50-59(61,15 \%)$ & $34(57 \%)$ & 0.62 & $0.33-1.18$ & 0.71 & $0.31-1.61$ \\
\hline $60+(52,12 \%)$ & $27(53 \%)$ & 0.53 & $0.27-1.05$ & 0.65 & $0.24-1.79$ \\
\hline \multicolumn{6}{|l|}{ Ethnicity } \\
\hline White $(348,75 \%)$ & $215(63 \%)$ & 1.00 & & 1.00 & \\
\hline Non-white $(119,25 \%)$ & $60(52 \%)$ & 0.64 & $0.42-0.98$ & 0.54 & $0.29-0.98$ \\
\hline \multicolumn{6}{|l|}{ Education Qualifications } \\
\hline None $(37,8 \%)$ & $16(43 \%)$ & 1.00 & & 1.00 & \\
\hline School education (147, 33 \%) & $79(55 \%)$ & 1.57 & $0.76-3.25$ & 1.00 & $0.34-2.90$ \\
\hline Higher education (260, $59 \%)$ & $170(66 \%)$ & 2.59 & $1.29-5.53$ & 1.67 & $0.57-4.84$ \\
\hline \multicolumn{6}{|l|}{ Health literacy score } \\
\hline Low $(64,14 \%)$ & $30(50 \%)$ & 1.00 & & 1.00 & \\
\hline Marginal (120, $26 \%)$ & $62(53 \%)$ & 1.13 & $0.61-2.10$ & 1.08 & $0.38-3.10$ \\
\hline Adequate $(282,60 \%)$ & $175(64 \%)$ & 1.77 & $1.01-3.10$ & 0.94 & $0.33-2.72$ \\
\hline \multicolumn{6}{|l|}{ Symptom knowledge change score } \\
\hline No change or decrease $(100,21 \%)$ & $33(37 \%)$ & 1.00 & & 1.00 & \\
\hline Small increase $(242,50 \%)$ & $144(60 \%)$ & 2.55 & $1.54-4.20$ & 2.68 & $1.32-5.44$ \\
\hline Large increase $(141,29 \%)$ & $101(73 \%)$ & 4.63 & $2.62-8.21$ & 4.21 & $1.95-9.13$ \\
\hline \multicolumn{6}{|l|}{ Barrier change score } \\
\hline No change or increase $(212,45 \%)$ & $104(49 \%)$ & 1.00 & & 1.00 & \\
\hline Small reduction $(188,40 \%)$ & $117(64 \%)$ & 1.82 & $1.22-2.73$ & 1.84 & $1.07-3.17$ \\
\hline Large reduction $(72,15 \%)$ & $57(79 \%)$ & 3.91 & $2.08-7.34$ & 4.60 & $1.91-11.04$ \\
\hline \multicolumn{6}{|l|}{ Anxiety change score } \\
\hline No change or increase $(234,58$ \%) & $138(61 \%)$ & 1.00 & & 1.00 & \\
\hline Small reduction $(128,32 \%)$ & $87(68 \%)$ & 2.02 & $0.97-4.18$ & 1.95 & $0.82-4.61$ \\
\hline Large reduction $(39,10 \%)$ & $20(51 \%)$ & 1.46 & $0.74-2.88$ & 1.39 & $0.63-3.07$ \\
\hline
\end{tabular}

short-term positive impact of the leaflet on symptom knowledge, perceived barriers and anxiety levels. It also reduced the median time the participants would wait before seeking help across all 12 symptoms. Furthermore, we have shown that this increase in symptom knowledge, and decrease in the number of barriers endorsed, were independently predictive of an increase in the number of symptoms for which these women would seek help promptly. Similar to previous research into information provision on testicular cancer [33], the inclusion of reassuring messages and a symptom checklist which gives women a clear course of action facilitated the uptake of the information while avoiding increased anxiety.
Providing women with knowledge of gynaecological cancer symptoms while addressing barriers to helpseeking is important to improve rates of early diagnosis. This is particularly true because the anatomical location of these types of cancer could mean that embarrassment and unwillingness to seek help may present more significant barriers than for other cancers. This may disproportionately impact women from Black, Asian and Minority Ethnic backgrounds [34], which may in part explain the persistent reticence shown by the non-white women in our study to anticipate seeking help. As education levels and health literacy were adjusted for, these cannot explain the large difference found for this group. Further research should investigate what might be added to or 
changed in such a leaflet to tackle the barriers to prompt help-seeking that are more pronounced in non-white women.

In addition to embarrassment, the non-specific nature of many symptoms of gynaecological cancers, for example bloating and change in bowel habits, has been found to be a barrier to prompt help seeking as women do not associate such symptoms with gynaecological cancers [14], and are less concerned about symptoms that do not specifically involve the reproductive organs [13]. This study showed that by simply highlighting these symptoms to women, they may be more willing to seek help when they notice these changes.

Our previous research with GPs showed that while they believed the leaflet was important, they were concerned about a potential increase in anxiety and consultation rates [17]. We found that the leaflet was able to reduce the anxiety scores of our participants. This effect was however not associated with an increase in intentions to seek help promptly. While a decrease in anxiety score is a positive effect as previous research has linked high levels of fear and anxiety about cancer to delays in help-seeking [35], the change in the mean anxiety score, although significant, was relatively small and as such may not have been big enough to affect help-seeking intentions. The ways of reducing anxiety and its effect on prompt help-seeking warrant further investigation.

The main strength of this study is that it presents a frequently-lacking quantitative evaluation of a low intensity intervention. Our study also benefitted from an ethnically diverse sample (25\% non-white compared to $14 \%$ in the general population [36]), with a wide age range, and adequate power to produce robust findings. Additionally, using a repeated measures design allowed us to measure changes over time, which showed large differences prospectively, albeit over a short time interval.

While strengthening the study and allowing us to assess changes over time, the test-retest design is also a potential weakness in that some of the effect seen on knowledge could have been the result of the women being more practised at the questions on the second completion of the questionnaire. A longer time before re-test was unfortunately not practical here, but despite this the results do provide a first, objective evaluation of the impact of the information provided. In addition, women may have been motivated to provide responses at $\mathrm{T} 2$ that were consistent with researchers' expectations of change (social desirability bias), particularly in relation to speed of help-seeking. As we did not measure social desirability, we cannot rule this out as a possibility.

The large changes in knowledge and barriers led to very large changes in anticipated help-seeking, with evidence of a 'dose response' relationship: larger changes in knowledge and barriers leading to larger changes in promptness of help-seeking. This suggests that the more difference we can make to these factors, the more impact there will be on help-seeking. Therefore, although this study can only demonstrate the short term impact, the large effect found implies great potential to make a longer term difference.

This study sample over-represented higher educational levels compared to the general population (54\% had a higher degree compared to $30 \%$ of the general population [37]) and was recruited from a population with an interest in or connection to cancer because recruitment took place at Cancer Research UK events. Those with higher socio-economic status, implied by the higher education levels, are a group more likely to take part in surveys [38], and so generalising must be done with caution. Despite this, there was a good spread of health literacy scores, which was comparable to that found in other studies [39, 40]. Furthermore, there is no reason to think that the women came to these events with any more knowledge of gynaecological cancers than other members of the public, as in this sample knowing someone with cancer was not found to be associated with increased knowledge of these symptoms (mean symptom knowledge score at T1 was 6.19 in those with no cancer experience $(n=42)$ and 6.62 in those with a friend or family member who had had cancer $(n=429) ; p=0.42)$.

Although these data were collected in 2011, there is little reason to believe that knowledge of symptoms or other barriers have changed substantially in the intervening time. Recent studies continue to find that women frequently misattribute the symptoms of gynaecological cancer, and that their help-seeking is influenced by barriers such as the demands of everyday life, or the anxiety that surrounds cancer $[14,41]$. The importance of exploring and addressing these factors in help-seeking behaviour remains undiminished and we believe our findings make a significant contribution.

Finally, this stage of testing involved measuring intentions only, not actual behaviour, however it has been found that the correlation between intentions and behaviour in prospective studies is 0.53 , which could be considered a large effect size based on Cohen's interpretation of correlations $[42,43]$. This part of the development, therefore, constituted a proof of concept, to support the next stage of testing and development in a primary care setting, assessing the impact of the leaflet on consultation rates (particularly in ethnic minority and socioeconomically deprived groups), investigations ordered and referrals made.

\section{Conclusions}

When developing written information aimed at changing behaviour, it is essential to carry out thorough testing in 
the target population to demonstrate the impact of the intervention on behavioural intention, and to understand the mechanism for that impact. This study shows that useful information can be gathered through the underused step of quantitative evaluation of a leaflet and as such indicates a method through which more effective patient information documents could be created. Improving rates of early diagnosis of cancer in the UK depends, in part, on ensuring the patient interval is kept as brief as possible. This study has shown that, as a minimum, intentions to seek help for gynaecological cancer symptoms can be improved through information leaflets which also address barriers to help-seeking and provide a tool with which the woman can approach her GP.

Efforts should now be focussed on trialling the leaflet in primary care settings and assessing its impact on help-seeking behaviours in the real world.

\section{Ethics approval and consent to participate}

We confirm all patient/personal identifiers have been removed or disguised so the patient/person(s) described are not identifiable and cannot be identified through the details of the story. All named authors have agreed to the submission and have contributed significantly to the manuscript, and it is not under consideration elsewhere. Ethical approval was granted by the UCL Research Ethics Committee (reference 1122/004), and we have observed appropriate ethical guidelines and legislation in conducting the study described in this paper.

\section{Endnotes}

${ }^{1}$ More information can be found http://www.cancerresearchuk.org/health-professional/prevention-and-awareness/cancer-awareness-roadshow and http://raceforlife. cancerresearchuk.org/index.html

\section{Additional file}

Additional file 1: Gynaecological Cancer Information Leaflet. (PDF 173 kb)

\begin{abstract}
Abbreviations
CAM: Cancer Awareness Measure; GP: General Practitioner; MRC: Medical Research Council; NAEDI: National Awareness and Early Detection Initiative; NICE: National Institute for Health and Care Excellence; NVS: Newest Vital Sign; STAI: State-Trait Anxiety Inventory; T1: Time 1; T2: Time 2; UCL: University College London; UK: United Kingdom.
\end{abstract}

\section{Competing interests}

The authors declare that they have no competing interests.

\section{Authors' contributions}

AS, JWar and JWal conceived of and designed the study. AS, MM and EB carried out the data collection. AS, MM, JWal and CFS contributed to the data analysis. All the authors have been involved in the drafting of the manuscript, given final approval of the submitted version and agree to be accountable for all aspects of the work.

\section{Acknowledgements}

We would like to thank all of the women who took part in this study and Katrin Haeussler for her help with the data analysis.

\section{Funding}

This research was funded by a grant from the National Awareness and Early Detection Initiative (NAEDI), reference number: A12209. The funder had no input into the conduct of the research, nor the decision to publish.

\section{Author details}

${ }^{1}$ Health Behaviour Research Centre, University College London, 1-19 Torrington Place, London WC1E 7HB, UK. ${ }^{2}$ Present address: Cancer Research UK Cancer Survival Group, London School of Hygiene and Tropical Medicine, London, UK. ${ }^{3}$ Present address: Health Services Research, School of Health

Sciences, City University London, London, UK.

Received: 15 January 2016 Accepted: 22 April 2016

Published online: 04 May 2016

\section{References}

1. Office for National Statistics. Cancer Incidence and Mortality in the United Kingdom, 2008-2010. Newport: ONS; 2012.

2. Modesitt SC, van Nagell JRJ. The impact of obesity on the incidence and treatment of gynecologic cancers: a review. Obstet Gynecol Surv. 2005;60: 683-92.

3. Hamilton W, Peters TJ, Bankhead C, Sharp D. Risk of ovarian cancer in women with symptoms in primary care: population based case-control study. Brit Med J. 2009;339:b2998.

4. Stapley S, Hamilton W. Gynaecological symptoms reported by young women: examining the potential for earlier diagnosis of cervical cancer. Fam Pract. 2011;28:592-8.

5. Rossing MA, Wicklund KG, Cushing-Haugen KL, Weiss NS. Predictive value of symptoms for early detection of ovarian cancer. J Natl Cancer I. 2010;102: 222-9.

6. Kirwan JM, Tincello DG, Herod JJ, Frost O, Kingston RE. Effect of delays in primary care referral on survival of women with epithelial ovarian cancer: retrospective audit. Brit Med J. 2002:324:148-51.

7. NICE. Suspected cancer: recognition and referral. London: National Institute for Health and Care Excellence; 2015.

8. Weller D, Vedsted P, Rubin G, Walter FM, Emery J, Scott S, et al. The Aarhus statement: improving design and reporting of studies on early cancer diagnosis. Brit J Cancer. 2012;106:1262-7.

9. Richards MA. The size of the prize for earlier diagnosis of cancer in England. Brit J Cancer. 2009:101:S125-9.

10. Thomson CS, Forman D. Cancer survival in England and the influence of early diagnosis: what can we learn from recent EUROCARE results? Brit J Cancer. 2009;3:6605399.

11. Low EL, Simon AE, Lyons J, Romney-Alexander D, Waller J. What do British women know about cervical cancer symptoms and risk factors? Eur J Cancer. 2012:48:3001-8.

12. Low EL, Waller J, Menon U, Jones A, Reid F, Simon AE. Ovarian cancer symptom awareness and anticipated time to help-seeking for symptoms among UK women. J Fam Plann Reprod Health Care. 2013;39:163-71.

13. Cooper CP, Polonec L, Stewart SL, Gelb CA. Gynaecologic cancer symptom awareness, concern and care seeking among US women: a multi-site qualitative study. Fam Pract. 2013;30:96-104.

14. Low EL, Whitaker KL, Simon AE, Sekhon M, Waller J. Women's interpretation of and responses to potential gynaecological cancer symptoms: a qualitative interview study. BMJ Open. 2015;5:e008082

15. Quaife $S L$, Forbes $L L L$, Ramirez AJ, Brain KE, Donnelly C, Simon AE, et al. Recognition of cancer warning signs and anticipated delay in help-seeking in a population sample of adults in the UK. Brit J Cancer. 2014;1 10:12-8.

16. Robb K, Stubbings S, Ramirez A, Macleod U, Austoker J, Waller J, et al. Public awareness of cancer in Britain: a population-based survey of adults. Brit J Cancer. 2009;101:S18-23.

17. Evans RE, Morris M, Sekhon M, Buszewicz M, Walter FM, Waller J, et al. Increasing awareness of gynaecological cancer symptoms: a GP perspective. Brit J Gen Pract. 2014;64:e372-80.

18. Whitaker KL, Macleod U, Winstanley K, Scott SE, Wardle J. Help seeking for cancer 'alarm' symptoms: a qualitative interview study of primary care patients in the UK. Brit J Gen Pract. 2015;65:e96-e105. 
19. Austoker J, Bankhead C, Forbes LJ, Atkins L, Martin F, Robb K, et al. Interventions to promote cancer awareness and early presentation: systematic review. Br J Cancer. 2009;101 Suppl 2:S31-9.

20. Robb KA, Miles A, Campbell J, Evans P, Wardle J. Can cancer risk information raise awareness without increasing anxiety? A randomized trial. Prev Med. 2006:43:187-90.

21. John H, Hale ED, Treharne GJ, Korontzis K, Obrenovic K, Carroll D, et al. Patient evaluation of a novel patient education leaflet about heart disease risk among people with rheumatoid arthritis. Musculoskeletal Care. 2011;9:194-9.

22. Heesen C, Schaffler N, Kasper J, Muhlhauser I, Kopke S. Suspected multiple sclerosis - what to do? Evaluation of a patient information leaflet. Mult Scler. 2009;15:1103-12.

23. Olamijulo JA, Duncan ID. Patient-based evaluation of a colposcopy information leaflet. J Obstet Gynaecol. 1997;17:394-8.

24. Nicolson D, Knapp P, Raynor DK, Spoor P. Written information about individual medicines for consumers. Cochrane DB Syst Rev. 2009;(2):CD002104.

25. Craig P, Dieppe P, Macintyre S, Michie S, Nazareth I, Petticrew M. Developing and evaluating complex interventions: the new Medical Research Council guidance. BMJ. 2008;337:a1655.

26. de Nooijer J, Lechner L, Candel M, de Vries H. Short- and long-term effects of tailored information versus general information on determinants and intentions related to early detection of cancer. Prev Med. 2004:38:694-703.

27. Weiss BD, Mays MZ, Martz W, Castro KM, DeWalt DA, Pignone MP, et al. Quick assessment of literacy in primary care: the newest vital sign. Ann Fam Med. 2005;3:514-22.

28. Rowlands G, Khazaezadeh N, Oteng-Ntim E, Seed P, Barr S, Weiss BD. Development and validation of a measure of health literacy in the UK: the newest vital sign. BMC Public Health. 2013;13:1471-2458.

29. Simon AE, Wardle J, Grimmett C, Power E, Corker E, Menon U, et al. Ovarian and cervical cancer awareness: development of two validated measurement tools. J Fam Plann Reprod Health Care. 2012;38:167-74.

30. Office for National Statistics. 2011 Census questions. Newport: ONS; 2008.

31. Stubbings S, Robb K, Waller J, Ramirez A, Austoker J, Macleod U, et al. Development of a measurement tool to assess public awareness of cancer. Brit J Cancer. 2009;101:S13-7.

32. Marteau TM, Bekker H. The development of a six-item short-form of the state scale of the Spielberger State-Trait Anxiety Inventory (STAI). Br J Clin Psychol. 1992;31:301-6.

33. Evans RE, Beeken RJ, Steptoe A, Wardle J. Cancer information and anxiety: applying the extended parallel process model. J Health Psychol. 2012;17: 579-89.

34. Marlow LAV, McGregor LM, Nazroo JY, Wardle J. Facilitators and barriers to help-seeking for breast and cervical cancer symptoms: a qualitative study with an ethnically diverse sample in London. Psycho-Oncol. 2014;23:749-57.

35. Smith LK, Pope C, Botha JL. Patients' help-seeking experiences and delay in cancer presentation: a qualitative synthesis. Lancet. 2005;366:825-31.

36. Office for National Statistics. Ethnicity and National Identity in England and Wales 2011. Newport: ONS; 2012

37. Office for National Statistics. Release: 2011 Census analysis, local area analysis of qualifications across England and Wales. Newport: ONS; 2014

38. Korkeila K, Suominen S, Ahvenainen J, Ojanlatva A, Rautava P, Helenius H, et al. Non-response and related factors in a nation-wide health survey. Eur J Epidemiol. 2001;17:991-9.

39. von Wagner C, Knight K, Steptoe A, Wardle J. Functional health literacy and health-promoting behaviour in a national sample of British adults. J Epidemiol Community Health. 2007;61:1086-90.

40. Harding C, Romanou E, Williams J, Peters M, Winkley J, Burke P, Hamer J, Jeram K, Nelson N, Rainbow B, Bond B and Shay M. Skills for Life Survey: Headline Findings. London, UK: Department for Business Innovations and Skills; 2011.

41. Balasooriya-Smeekens C, Walter FM, Scott S. The role of emotions in time to presentation for symptoms suggestive of cancer: a systematic literature review of quantitative studies. Psycho-Oncol. 2015;24:1594-604.

42. Sheeran P. Intention-Behavior Relations: A Conceptual and Empirical Review. Eur Rev of Soc Psychol: John Wiley \& Sons, Ltd; 2005. p. 1-36.

43. Cohen J. A power primer. Psychol Bull. 1992;112:155-9.

\section{Submit your next manuscript to BioMed Central and we will help you at every step:}

- We accept pre-submission inquiries

- Our selector tool helps you to find the most relevant journal

- We provide round the clock customer support

- Convenient online submission

- Thorough peer review

- Inclusion in PubMed and all major indexing services

- Maximum visibility for your research

Submit your manuscript at www.biomedcentral.com/submit

) Biomed Central 